\title{
REDECA
}

CI ÊNCIAS CONTÁBEIS

ATUÁRIA E MÉTODOS QUANTITATIVOS

\section{SPED - SISTEMA PÚBLICO DE ESCRITURAÇÃO DIGITAL: PERCEPÇÃO DAS EMPRESAS DE AUDITORIA EM RELAÇÃO OS IMPACTOS DE SUA ADOÇÃO}

\author{
Ana Paula Medeiros Ferreira ${ }^{1}$ \\ Cintia Maria Cardoso Attanasio ${ }^{2}$ \\ Maria Júlia Frezarin Martins ${ }^{3}$ \\ Liliane Cristina Segura ${ }^{4}$ \\ Henrique Formigoni ${ }^{5}$
}

\begin{abstract}
Resumo
O presente artigo aplicado pretende fazer uma contribuição aos principais impactos da implementação do Sistema Público de Escrituração Digital (SPED), em especial quanto a obrigação acessória relacionada ao imposto de renda da pessoa jurídica -Escrituração Fiscal Contábil (ECF), sob o prisma de uma grande empresa de auditoria e consultoria tributária. Seu escopo foi realizar um levantamento dos principais impactos - tanto internos, quanto àqueles relacionados aos clientes - gerados pela implementação da ECF, sob o prisma de uma empresa de auditoria e consultoria tributária, que tem o dever de revisar e auditar esses arquivos. Para tanto, realizamos um comparativo entre a obrigação acessória anterior Declaração de Imposto de Renda da Pessoa Jurídica (DIPJ) e a obrigação acessória vigente (ECF), que abrangeu diversos aspectos para verificar a diferença os procedimentos adotados nas análises dessas duas obrigações acessórias, bem como identificar demais impactos. A metodologia empregada no estudo foi de natureza qualitativa, visto que aplicamos um questionário a um grupo de funcionários da empresa de auditoria que trabalham diretamente com a ECF. Os resultados obtidos foram analisados e interpretados e restou demonstrando que a implementação da ECF trouxe diversas mudanças no comportamento e procedimentos aplicados para a elaboração dessa obrigação acessória, tanto dentro da empresa de auditoria, quanto nos clientes. Essas mudanças foram motivadas pela maior complexidade de informações necessárias, a inclusão de informações não originárias do departamento fiscal, a alta tecnologia envolvida e os cruzamentos automáticos que o sistema do Governo faz, exigindo mais atenção e cuidado por parte dos prestadores da informação, quando comparado com a DIPJ.
\end{abstract}

Palavras-chave: DIPJ; EFC; Empresa de auditoria; SPED Fiscal

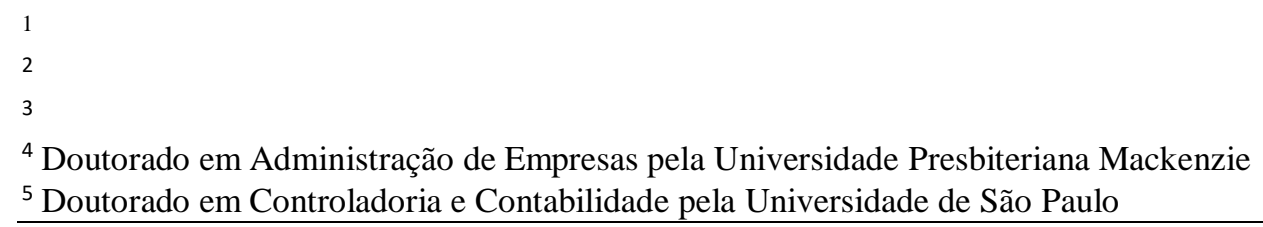




\title{
REDECA
}

\section{CI ÊNCIAS CONTÁBEIS}

\begin{abstract}
This article was intended to contribute on the study regarding thein main impacts of the implementation of the Public Digital Bookkeeping System (SPED), especially concerning to the ancillary obligation related to corporate income tax - Accounting Tax Scheduling (ECF), under the prism of a large audit and tax consultancy firm. The scope is to investigate and analyze main impacts, with regard to the firm and its clients, caused on the firma and by the implementation of the ECF, under the prism of an audit and consulting firm that has the duty to review and audit this ancillary obligation. For this purpose, we have made a comparison between the previous ancillary obligation (DIPJ) and this current obligation (ECF) on the following aspects: to determine the engagement of others department to review the ECF in opposition to DIPJ; identify the creation of new services branch to offer to our clients; verify the development of new technologies; to assess the different procedures applied on the analysis of these two accessory obligation; identify other impacts that were appointed on the survey.

The methodology employed in this paper has the qualitative nature since we applied a survey to the firm's employees that work directly with the ECF. The results of the survey were analyzed and interpreted and it demonstrated that the implementation of ECF implied in several changes, either to the firm or to its clients, with regard to this ancillary obligation. These changes were motivated by the higher complexity of information required, the addition of non-originating information from the tax department, the high technology involved and the automatic crosscheck that the Government system has, requiring more caution from the taxpayers if compared to DIPJ.
\end{abstract}

Key words: DIPJ; EFC; Empresa de auditoria; SPED Fiscal 
Gimenez, L., Oliveira, A. B. S., Carvalho, F. J. P.; SPED - Sistema Público de Escrituração Digital: Percepção das Empresas de Auditoria em relação os impactos de sua adoção

\section{Introdução}

Os avanços tecnológicos possuem grande importância nas mais diversas áreas do cotidiano da sociedade atual, são cada mais ágeis, expressivos e notórios para todos. Esses avanços ensejaram a adaptação dos usuários através de mudanças no seu comportamento diário e nos procedimentos adotados ao realizarem determinadas atividades. Dentre os usuários afetados, destaca-se o governo brasileiro que vislumbrou a necessidade de implementar e desenvolver melhorias no setor de fiscalização e controle público.

Baseado em modelos de governos eletrônicos de países como Espanha, Chile e México, o Brasil implementou por meio do Decreto $\mathrm{n}^{\circ}$ 6.022, de 22 de janeiro de 2007, o Sistema Público de Escrituração Digital - SPED, que tem como principal objetivo padronizar o compartilhamento das informações contábeis e fiscais dos contribuintes, servindo como facilitador às autoridades fiscais no que diz respeito ao acesso às informações e cruzamentos de dados eletrônicos (SEBOLD et al., 2012).

O Governo faz parte do grupo de interessados nas informações prestadas pelas empresas (Hendriksen \& Van-Breda, 1999). Por se tratar de órgão arrecadador, a situação econômica e financeira da empresa é de extrema relevância para este. Em razão dessa importância deve existir grande responsabilidade e cautela nos dados que são apresentados pelos contribuintes.

Com a implantação do Sistema Público de Escrituração Digital - SPED, os contribuintes não prestarão mais as informações para cada um dos órgãos fiscalizadores em papel, e sim por meio eletrônico, através de um sistema online. Os arquivos irão para uma base de dados única, e, serão compartilhados pelas autoridades fiscais e pelos demais órgãos autorizados. O Governo Federal, o Estadual, e as instituições autorizadas poderão acessar diretamente o sistema, obtendo as informações desejadas.

Dentro do cenário do governo eletrônico, especificamente no que tange ao SPED, que será melhor detalhado nos próximos capítulos desse trabalho, a pesquisa foi desenvolvida teve como ênfase as análises relacionadas à Escrituração Contábil e Fiscal - ECF, que substituiu a Declaração de Informações Econômico-Fiscais da Pessoa Jurídica - DIPJ, a partir do ano calendário de 2014.

No decorrer da pesquisa foram identificadas e demonstradas as principais mudanças e impactos que esse novo sistema trouxe para uma das grandes empresas de auditoria e consultoria tributária, que por questões de confidencialidade das informações prestadas, não será citado a sua razão social.

Baseado na legislação vigente, serão reportadas as principais repercussões e resultados gerados no período de implementação, além da consolidação das eventuais melhorias e desafios inerentes ao novo procedimento exigido pelo fisco.

A Receita Federal do Brasil - RFB - implementou o programa validador da ECF que, embora esteja em vigor há quase 4 anos, ainda restam dúvidas e preocupações, quanto a determinados procedimentos e informações pertinentes a esta obrigação acessória. Desta forma, o aumento rigoroso no nível de detalhes, obrigou as empresas a alterarem sua rotina de forma radical.

Os profissionais dos setores contábil e fiscal foram obrigados a investirem maior tempo e dedicação nos projetos relacionados a Escrituração Contábil Fiscal - ECF. O mesmo aplica-se 
Gimenez, L., Oliveira, A. B. S., Carvalho, F. J. P.; SPED - Sistema Público de Escrituração Digital: Percepção das Empresas de Auditoria em relação os impactos de sua adoção

às empresas de auditoria e consultoria tributária, que são contratadas para realizar a revisão ou até mesmo o preenchimento da referida obrigação acessória. De forma geral, todos os envolvidos necessitam de maior preparação para atender as exigências trazidas pelo novo programa.

Dessa forma, segundo a RBF (BRASIL, 2017a) a tecnologia desenvolvida pelo governo, trará benefícios em todos os setores, pois da mesma forma que facilitará a fiscalização dos procedimentos adotados pelas empresas, isso significa que os contribuintes terão maior controle dos documentos e informações prestadas às autoridades fiscais.

A pesquisa abordada nesse trabalho tem como objetivo a avaliação dos impactos gerados nas empresas de auditoria e consultoria tributária após a implementação do SPED. Para melhor análise dos dados encontrados, a ECF foi a obrigação acessória escolhida como foco desse estudo, dentro do âmbito do governo eletrônico.

Desse modo, o presente estudo transcorrerá especificamente sobre as seguintes temáticas: tempo depreendido para execução dos projetos que envolvem a ECF; Do envolvimento de outros departamentos, além do tributário para a realização desses projetos, e a essencialidade dessa integração; Da criação de novos serviços ao serem oferecidos aos clientes, após a implementação da ECF e o grau de adesão destes; Das mudanças nos ambientes internos dos clientes; Da necessidade da tecnologia para obter as informações necessárias à transmissão da obrigação acessória; Da dimensão do tempo e valor investidos em treinamentos dos profissionais dessa empresa de auditoria e consultoria tributária, para torná-los aptos à executarem o preenchimento e a revisão da ECF, além da avaliação da importância desses treinamentos na prática; Da complexidade das informações necessárias para entregar a ECF, quando comparado com a DIPJ; Da diferença nas análises realizadas nos projetos de revisão e preenchimento das duas obrigações acessórias; Dos impactos gerais percebidos nos clientes; Da percepção quanto à receita obtida com os projetos relacionados à ECF, quando comparados com a DIPJ.

Ao final, os resultados da pesquisa demonstram as principais repercussões ocasionadas, referentes ao conteúdo da pesquisa descrito acima, no que tange às exigências da nova obrigação acessória instituída pelo órgão governamental.

Nesse contexto, o presente trabalho se propõe a contribuir com a produção acadêmica e técnica sobre o assunto, tendo em vista a ausência de trabalhos com os mesmos objetivos.

\section{Referencial Teórico}

O Sistema Público de Escrituração Digital - SPED, instituído pelo Decreto No 6.022, de 22 de janeiro de 2007, foi umas das medidas adotadas no Programa de Aceleração do Crescimento do Governo Federal - PAC 2007-2010 - para aperfeiçoar o Sistema Tributário Nacional.

Sua concepção tem como principal objetivo modernizar a forma que as obrigações acessórias são declaradas e transmitidas às autoridades fiscais, através da substituição dos livros físicos e demais documentos fiscais e contábeis, escritos em papel, por documentos em formato eletrônico, com certificação digital.

Essa nova forma de apresentação de informações às autoridades fiscais tem como diretrizes: racionalizar, sistematizar e padronizar os documentos a serem transmitidos, melhorar a 
Gimenez, L., Oliveira, A. B. S., Carvalho, F. J. P.; SPED - Sistema Público de Escrituração Digital: Percepção das Empresas de Auditoria em relação os impactos de sua adoção

qualidade e a integridade da informação prestada, garantir a segurança e validade jurídica de tais documentos, e a promover a integração administrativa entre as três esferas governamentais: municipal, estadual e federal, na troca de informações e na fiscalização tributária (BRASIL, 2017a).

As diretrizes e objetivos do SPED são fundamentados em princípios da Constituição da República Federativa do Brasil, que servem como referência e orientação para a atuação dos órgãos de administração tributária, tanto na esfera federal quanto estadual e municipal.

Dos referidos fundamentos constitucionais, de início, cabe destacar os princípios gerais da administração pública: Legalidade, Impessoalidade, Moralidade, Publicidade e Eficiência, previstos no caput do artigo 37 da Constituição. (CULAU; FORTES, 2006)

O SPED, seus objetivos e diretrizes, podem ser entendidos como instrumentos de efetivação dos princípios da administração pública, pois representam a adoção de informações públicas princípio da Publicidade, estabelecidas por meio de normas produzidas com validade jurídica princípio da Legalidade, aplicáveis indistintamente a todos os contribuintes - princípio da Impessoalidade, de acordo com preceitos éticos, não discriminatórios, e não confiscatórios princípio da Moralidade, conforme a padronização e os meios eletrônicos especificados, para tornar a transmissão de informações mais rápida, segura, detalhada e eficiente - princípio da Eficiência.

Um outro princípio que serviu como referência para a criação do SPED é o previsto no inciso XXII do artigo 37 da Constituição, que prevê a necessidade de integração, e compartilhamento de informações, entre as administrações tributárias da União, Estados e Municípios. A seguir transcreve-se o referido dispositivo:

\begin{abstract}
Art.37. (...)
XXII - as administrações tributárias da União, dos Estados, do Distrito Federal $e$ dos Municípios, atividades essenciais ao funcionamento do Estado, exercidas por servidores de carreiras específicas, terão recursos prioritários para a realização de suas atividades e atuarão de forma integrada, inclusive com o compartilhamento de cadastros e de informações fiscais, na forma da lei ou convênio. (BRASIL,1988)
\end{abstract}

Cumpre ressaltar que acima foram elencados apenas alguns dos princípios que fundamentam a criação do SPED, no entanto existem outros princípios constitucionais, de direito administrativo e direito tributário relacionados ao tema, entretanto o presente trabalho não pretende exaurir o tema, apenas apresentar o referencial teórico e princípio lógico em que se insere o SPED.

No contexto da implementação do SPED e suas obrigações acessórias, as autoridades governamentais promoveram três projetos de modernização e informatização dos dados fiscais e contábeis, a Escrituração Contábil Digital - ECD, a Escrituração Fiscal Digital - EFD- e a Nota Fiscal Eletrônica - NF-e, (BRASIL, 2017b).

Posteriormente, os referidos projetos - ECD, EFD e NF-e - se desdobraram em outras novas obrigações contábeis e fiscais digitais (BRASIL, 2017b). Nesse sentido, o atual universo de obrigações acessórias no âmbito do SPED pode ser representado de acordo com o esquema (Figura 1): 
Gimenez, L., Oliveira, A. B. S., Carvalho, F. J. P.; SPED - Sistema Público de Escrituração Digital: Percepção das Empresas de Auditoria em relação os impactos de sua adoção

Quadro 1 - Obrigações acessórias no âmbito do SPED:

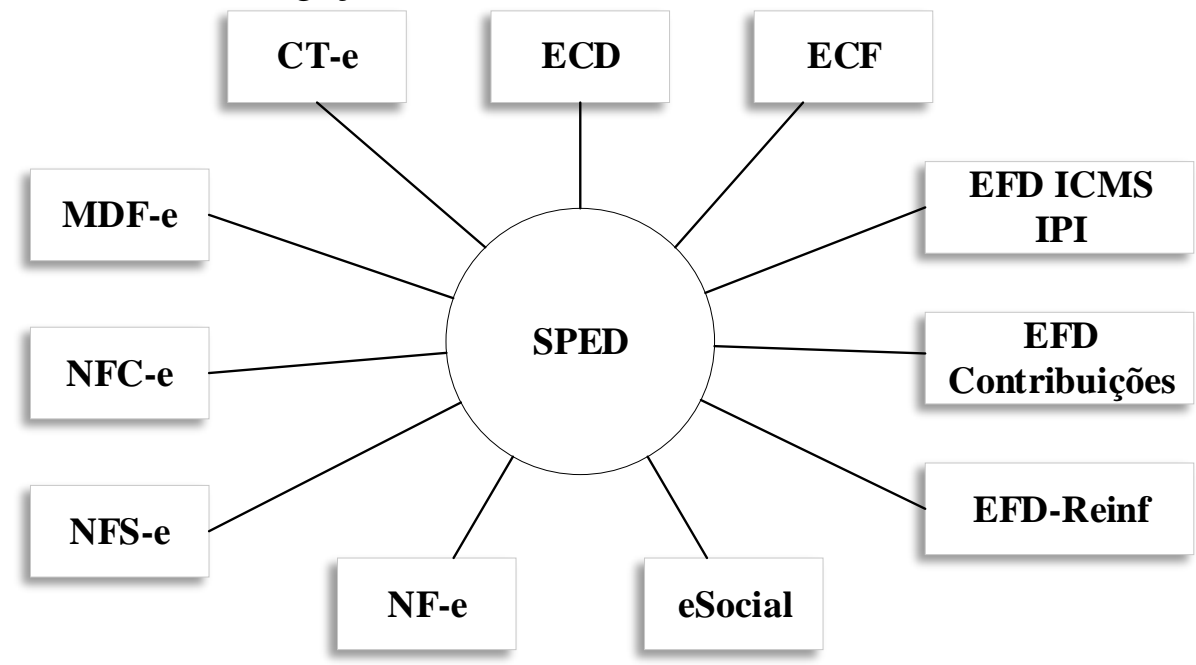

Fonte: Elaboração própria.

Tendo em vista que as obrigações acessórias criadas no âmbito do SPED são todas eletrônicas, para cada caso foi criada uma seção no portal do SPED no site da Receita Federal do Brasil. Esse portal e suas seções são os principais meios de comunicação entre os contrib uintes e as autoridades fiscais, além disso, eles são as principais fontes para obtenção de informações sobre o SPED e suas diferentes obrigações fiscais e contábeis.

O Conhecimento de Transporte Eletrônico - CT-e, de acordo com o portal nacional do SPED (BRASIL, 2017c), pode ser conceituado da seguinte forma:

(...) documento de existência apenas digital, emitido e armazenado eletronicamente, com o intuito de documentar, para fins fiscais, uma prestação de serviço de transporte de cargas realizada por qualquer modal (Rodoviário, Aéreo, Ferroviário, Aquaviário e Dutoviário). Sua validade jurídica é garantida pela assinatura digital do emitente (garantia de autoria e de integridade) e pela recepção e autorização de uso, pelo Fisco.

A Escrituração Contábil Digital - ECD, segundo o portal nacional do SPED (BRASIL, 2017d): (...) tem por objetivo a substituição da escrituração em papel pela escrituração transmitida via arquivo, ou seja, corresponde à obrigação de transmitir, em versão digital, os seguintes livros:

I - Livro Diário e seus auxiliares, se houver;

II - Livro Razão e seus auxiliares, se houver; //

III - Livro Balancetes Diários, Balanços e fichas de lançamento comprobatórias dos assentamentos neles transcritos.

A Escrituração Contábil Fiscal - ECF, obrigação acessória relativa ao Imposto de Renda da Pessoa Jurídica e à Contribuição Social sobre o Lucro Líquido, é descrita pelo portal nacional do SPED (BRASIL, 2017e), como:

A Escrituração Contábil Fiscal (ECF) substitui a Declaração de Informações Econômico-Fiscais da Pessoa Jurídica (DIPJ), a partir do ano-calendário 2014, com entrega prevista para o último dia útil do mês de julho do ano posterior ao do período da escrituração no ambiente do Sistema Público de Escrituração Digital (Sped). Portanto, a DIPJ está extinta a partir do ano-calendário 2014.

A Escrituração Fiscal Digital ICMS IPI - EFD ICMS/IPI, obrigação acessória relativa às apurações do ICMS e do IPI, é descrita pelo portal nacional do SPED (BRASIL, 2017f), como:

A Escrituração Fiscal Digital - EFD é um arquivo digital, que se constitui de um conjunto de escriturações de documentos fiscais e de outras informações de interesse 
Gimenez, L., Oliveira, A. B. S., Carvalho, F. J. P.; SPED - Sistema Público de Escrituração Digital: Percepção das Empresas de Auditoria em relação os impactos de sua adoção

dos Fiscos das unidades federadas e da Secretaria da Receita Federal do Brasil, bem como de registros de apuração de impostos referentes às operações e prestações praticadas pelo contribuinte.

A Escrituração Fiscal Digital Contribuições - EFD Contribuições, obrigação acessórias relativa às apurações do PIS, da COFINS e da Contribuição Previdenciária sobre a Receita Bruta, é descrita pelo portal nacional do SPED (BRASIL, 2017g), como:

A EFD-Contribuições trata de arquivo digital instituído no Sistema Público de Escrituração Digital - SPED, a ser utilizado pelas pessoas jurídicas de direito privado na escrituração da Contribuição para o PIS/Pasep e da Cofins, nos regimes de apuração não-cumulativo elou cumulativo, com base no conjunto de documentos e operações representativos das receitas auferidas, bem como dos custos, despesas, encargos e aquisições geradores de créditos da não cumulatividade.

A Escrituração Fiscal Digital de Retenções e Outras Informações Fiscais - EFD-Reinf obrigação acessórias relativa às apurações dos tributos retidos na fonte, é descrita pelo portal nacional do SPED (BRASIL, 2017h), como:

Tem por objeto a escrituração de rendimentos pagos e retenções de Imposto de Renda, Contribuição Social do contribuinte exceto aquelas relacionadas ao trabalho $e$ informações sobre a receita bruta para a apuração das contribuições previdenciárias substituídas.

O eSocial, de acordo com o portal nacional do SPED (BRASIL, 2017i), pode ser conceituado da seguinte forma:

O eSocial é um projeto do governo federal e um instrumento de unificação da prestação das informações referentes à escrituração das obrigações fiscais, previdenciárias e trabalhistas e tem por finalidade padronizar sua transmissão, validação, armazenamento e distribuição, constituindo um ambiente nacional.

A Nota Fiscal Eletrônica - NF-e - é conceituada em seu portal (BRASIL, 2017j) como:

Podemos conceituar a Nota Fiscal Eletrônica como sendo um documento de existência apenas digital, emitido e armazenado eletronicamente, com o intuito de documentar, para fins fiscais, uma operação de circulação de mercadorias ou uma prestação de serviços, ocorrida entre as partes. Sua validade jurídica é garantida pela assinatura digital do remetente (garantia de autoria e de integridade) e a Autorização de uso fornecida pelo Fisco, antes da ocorrência do fato gerador.

A Nota Fiscal de Serviços Eletrônica - NFS-e, segundo o portal nacional do SPED (BRASIL, 2017k):

O Projeto Nota Fiscal de Serviços Eletrônica (NFS-e) está sendo desenvolvido de forma integrada, pela Receita Federal do Brasil (RFB) e Associação Brasileira das Secretarias de Finanças das Capitais (Abrasf), atendendo o Protocolo de Cooperação ENAT $n^{\circ}$ 02, de 7 de dezembro de 2007, que atribuiu a coordenação e a responsabilidade pelo desenvolvimento e implantação do Projeto da NFS-e.

A Nota Fiscal de Serviços Eletrônica (NFS-e) é um documento de existência digital, gerado e armazenado eletronicamente em Ambiente Nacional pela RFB, pela prefeitura ou por outra entidade conveniada, para documentar as operações de prestação de serviços.

A Nota Fiscal de Consumidor Eletrônica - NFC-e, segundo o portal nacional do SPED (BRASIL, 20171):

A Nota Fiscal de Consumidor Eletrônica - NFC-e - é um documento de existência apenas digital, emitido e armazenado eletronicamente, com o intuito de documentar as operações comerciais de venda presencial ou venda para entrega em domicílio a consumidor final (pessoa física ou jurídica) em operação interna e sem geração de crédito de ICMS ao adquirente.

O Manifesto Fiscal Digital - MDF-e, segundo o portal nacional do SPED (BRASIL, 2017m): Manifesto Eletrônico de Documentos Fiscais (MDF-e) é o documento emitido e armazenado eletronicamente, de existência apenas digital, para vincular os documentos fiscais transportados na unidade de carga utilizada, cuja validade 
Gimenez, L., Oliveira, A. B. S., Carvalho, F. J. P.; SPED - Sistema Público de Escrituração Digital: Percepção das Empresas de Auditoria em relação os impactos de sua adoção

jurídica é garantida pela assinatura digital do emitente e autorização de uso pelo Ambiente Autorizador.

Tendo em vista a complexidade e o nível de detalhe das informações a serem prestadas no âmbito do SPED, todas as partes envolvidas: a administração pública, os contribuintes, e os terceiros que se utilizam dessas informações - contadores, advogados, empresas de auditoria e consultoria, bancos, etc. (IOB, 2006), foram impactados a partir da implementação das novas soluções fiscais digitais do SPED.

Além dos impactos decorrentes da aplicação dos princípios mencionados acima- legalidade, impessoalidade, moralidade, publicidade, eficiência e integração entre as autoridades fiscais, a administração pública também foi impactada pela necessidade de adequação de seus profissionais da área de execução de auditoria fiscal às novas soluções digitais e de tecnologia da informação e comunicação (CONDÉ; QUINTAL, 2015).

Quanto ao impacto da implementação do SPED nos contribuintes, verificamos que esse tema já foi objeto de diversos trabalhos, que tratam dos impactos aplicáveis a determinados setores da economia, tais como o setor têxtil, estudado por Alberti (2016), o setor de alimentação, estudado por Paixão, Lima e Albuquerque (2015), e o setor de transporte de cargas, estudado por Moretti (2013).

Além das partes diretamente envolvidas - contribuintes e administração tributária, alguns terceiros (IOB, 2006), mediante autorização, também têm acesso, e utilizam as informações fiscais e contábeis das empresas. São, entre outros, os bancos, que necessitam de informações financeiras sobre as empresas, os advogados, que utilizarão essas informações para fundamentar trabalhos de consultoria tributária, ou como provas em suas defesas e petições, os escritórios de contabilidade, envolvidos na preparação desses documentos, e as empresas de auditoria e consultoria, que recebem essas informações no âmbito da análise das demonstrações financeiras, ou no âmbito da prestação de serviços de assessoria fiscal.

Esses terceiros também serão afetados pelas mudanças impostas pela implementação das soluções de tecnologia e detalhamento de informações decorrentes das obrigações do SPED.

Foi verificado que existem trabalhos acadêmicos que estudam os impactos do SPED nos escritórios de contabilidade, os quais elencamos alguns:

Ruschel, Frezza e Utzig (2011), por meio de uma pesquisa descritiva, realizaram na cidade de Chapecó, onde verificaram os desafios e perspectivas do profissional contábil daquela localidade com a implementação do SPED Fiscal. O estudou concluiu que o SPED está influenciando direta e positivamente os profissionais da área contábil, especialmente quanto a fidedignidade e qualidade dos dados apresentados. Julgou ainda existir uma limitação de profissionais capacitados ao SPED.

Por outro lado, Veiga (2015) analisou o impacto do SPED em quinze empresas situadas em Dourados-MS, através da coleta de dados em resposta a um questionário aplicado aos profissionais contadores destas empresas. A conclusão foi de que os profissionais da área contábil responsáveis por essas empresas, apesar de terem levantadas vários questionamentos no começo, vislumbraram vários benefícios e oportunidades com a implantação do SPED. Entretanto, os profissionais evidenciaram que o profissional da área de TI (Tecnologia da Informação) tem um papel fundamental na implementação do SPED.

Por fim, Sanomia (2011), analisou o impacto do advento do SPED nos escritórios de contabilidade dos municípios de MUNICÍPIO DE CACOAL- RO, verificou as rotinas 
Gimenez, L., Oliveira, A. B. S., Carvalho, F. J. P.; SPED - Sistema Público de Escrituração Digital: Percepção das Empresas de Auditoria em relação os impactos de sua adoção

operacionais que foram afetadas nos escritórios de contabilidade e descreveu quais as principais mudanças e seus impactos, por meio de uma análise de natureza qualitativa, pesquisa de campo, descritiva e exploratória. Concluiu-se que a implementação do SPED trouxe bons resultados e proporcionou maior agilidade nas atividades desenvolvidas nos escritórios, bem como propiciou oportunidades de para trabalhos mais gerenciais.

Pelo exposto, não identificamos trabalhos específicos sobre a análise dos efeitos da implementação das obrigações do SPED nas empresas de auditoria e consultoria.

\section{Procedimentos Metodológicos}

A transmissão da ECF, obrigação acessória objeto desse estudo, é uma obrigação anual de todas as pessoas jurídicas sejam elas tributadas pelo lucro real, arbitrado ou presumido, conforme a Instrução Normativa - IN - da RFB no 1.422/2013, e alterações posteriores. Há algumas exceções à essa obrigatoriedade, também determinadas nessa IN, mas que não será escopo dessa pesquisa. A escolha dessa obrigação acessória foi baseada na sua relevância para todos os usuários das informações econômicas-fiscais.

A pesquisa será realizada através da aplicação de um questionário e posterior coleta de dados. Para Gerhardt, Silveira., e Toldo, (2009), questionário é definido como:

É um instrumento de coleta de dados constituído por uma série ordenada de
perguntas que devem ser respondidas por escrito pelo informante, sem a presença do
pesquisador. Objetiva levantar opiniões, crenças, sentimentos, interesses,
expectativas, situaçóes vivenciadas. A linguagem utilizada no questionário deve ser
simples e direta, para que quem vá responder compreenda com clareza o que está
sendo perguntado.

O método de pesquisa utilizado será o qualitativo. É importante mencionar, que os métodos qualitativo e quantitativo não são opostos. Divergem no tocante à forma e à ênfase, sendo que os qualitativos trazem como contribuição ao trabalho de pesquisa uma mistura de procedimentos de cunho racional e intuitivo capazes de contribuir para a melhor compreensão dos fenômenos (POPE; MAYS, 1995).

A pesquisa qualitativa não se preocupa com representatividade numérica, mas, sim, com o aprofundamento da compreensão de um grupo social, de uma organização, etc. Os pesquisadores que adotam essa metodologia, opõem-se ao pressuposto que defende um modelo único de pesquisa para todas as ciências, já que as ciências sociais têm sua especificidade, o que pressupõe uma metodologia própria. Assim, os pesquisadores qualitativos recusam o modelo positivista aplicado ao estudo da vida social, uma vez que o pesquisador não pode fazer julgamentos nem permitir que seus preconceitos e crenças contaminem a pesquisa. (GOLDENBERG, 1997).

Adicionalmente, na pesquisa qualitativa, o cientista é ao mesmo tempo o sujeito e o objeto de suas pesquisas. O desenvolvimento da pesquisa é imprevisível. O conhecimento do pesquisador é parcial e limitado. O objetivo da amostra é de produzir informações aprofundadas e ilustrativas: seja ela pequena ou grande, o que importa é que ela seja capaz de produzir novas informações (DESLAURIERS, 1991 apud GERHARDT, 2009) 
Gimenez, L., Oliveira, A. B. S., Carvalho, F. J. P.; SPED - Sistema Público de Escrituração Digital: Percepção das Empresas de Auditoria em relação os impactos de sua adoção

Desta forma, o método utilizado tem como objetivo levantar dados, lapidar o grande volume de informações brutas recebidas e interpretá-las de maneira a fornecer informações aos usuários do governo eletrônico.

O questionário foi aplicado sobre uma amostra da população que é composto por funcionários de uma grande empresa de auditoria e consultoria tributária. As informações constantes nesse documento serão formuladas considerando os seguintes aspectos:

$\checkmark \quad$ Cargo do profissional (gerencial ou operacional);

$\checkmark \quad$ Vivência aos modelos de obrigações acessórias anteriores ao SPED;

$\checkmark \quad$ Perguntas relacionadas aos impactos nos clientes, através de entrevista aberta para posterior avaliação das informações recebidas;

$\checkmark \quad$ Perguntas relacionadas aos impactos internos, através de entrevista aberta para posterior avaliação das informações recebidas; e

$\checkmark \quad$ Impactos imediatos à mudança e ao longo prazo.

Com base nos resultados extraídos, foram demonstradas as principais tendências e impactos causados aos usuários e elaboradores das informações contábeis e fiscais. A análise foi realizada utilizando as respostas obtidas visando apresentar informações úteis para os contribuintes e para as empresas em geral, no que tange as exigências da ECF.

\section{Análise dos Dados}

As análises deste trabalho foram baseadas nos resultados obtidos através de um questionário, elaborado com a intenção de identificar os principais impactos e diferenças entre a ECF e DIPJ. Desta forma, foram desenvolvidas cerca de 21 (vinte e uma) questões destinadas aos profissionais de uma grande empresa de auditoria e consultoria tributária e contábil.

Com esse questionário foi possível angariar informações a respeito do tempo necessário para realizar os projetos relacionados à nova obrigação acessória, análise do envolvimento de outros departamentos, além do tributário para a realização desses projetos, e a essencialidade dessa integração.

Constatou-se também os impactos gerais produzidos nos clientes, a importância da tecnologia, o tempo e valores investidos em treinamentos, a receita obtida com os novos projetos na empresa de auditoria e consultoria, e por fim, a pesquisa possibilitou a demonstração detalhada da complexidade das informações necessárias no momento da transmissão da ECF e principais diferenças da referida obrigação acessória quando comparada com a DIPJ.

Dentre as vinte respostas obtidas, a maioria dos profissionais são graduados em direito, sendo que uma parcela menor possui formação em ciências contábeis e quanto ao tempo de experiência na empresa esta informação apresentou variação entre dois e dezoito anos.

Na percepção dos entrevistados, considerando suas experiências e a carga de trabalho para cumprir com as obrigações fiscais, após a implementação da ECF, o tempo dedicado aos projetos de revisão e preenchimento dessa obrigação acessória aumentou significativamente quanto comparado aos mesmos trabalhos executados no período da DIPJ, conforme demonstrado a seguir: 
Gimenez, L., Oliveira, A. B. S., Carvalho, F. J. P.; SPED - Sistema Público de Escrituração Digital: Percepção das Empresas de Auditoria em relação os impactos de sua adoção

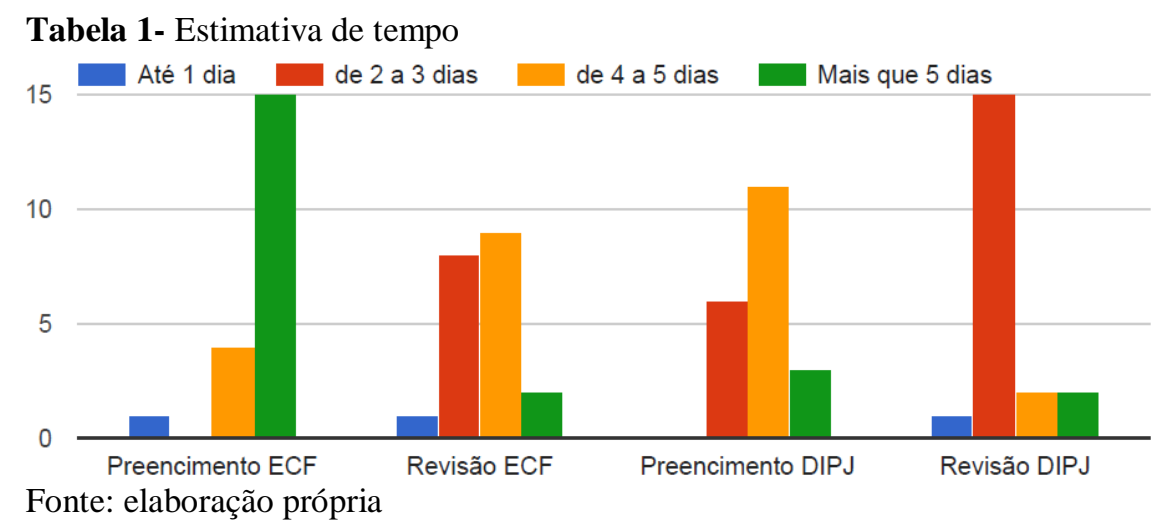

Diante do gráfico é possível observar que em relação ao preenchimento da ECF, a maioria entende que é necessário mais que 5 dias dos profissionais envolvidos para conclusão do projeto, sendo que anteriormente, no preenchimento da DIPJ, este prazo não ultrapassava a 5 dias, podendo ser realizado em prazo inferior.

Tratando da revisão, atualmente a ECF exige cerca de 2 a 5 dias, quando na DIPJ a maioria dos trabalhos eram elaborados em no máximo de 2 a 3 dias. Portanto, independente do projeto realizado, é notório o aumento da carga horária dos profissionais.

Outro aspecto importante está relacionado à necessidade de integração de outras áreas da empresa, com os profissionais do quadro técnico tributário, nesse sentido $90 \%$ dos entrevistados consideram essa integração essencial para a consecução dos trabalhos.

O principal motivo mencionado na entrevista, está relacionado a complexidade da nova obrigação acessória (ECF), além disso, muitos entendem que falta de comunicação entre os departamentos internos, pode gerar falhas no preenchimento.

Desta forma, é necessário que os especialistas de cada área, dentre eles (i) recursos humanos, (ii) contabilidade, (iii) financeiro e (iv) fiscal, mantenham contato direto com os profissionais responsáveis pelo preenchimento da referida escrituração.

Conforme relatado, as empresas funcionam como uma engrenagem, e, portanto, precisam que todos os departamentos trabalhem de forma harmônica, para obter informações confiáveis e evitar o trabalho em duplicidade.

Para muitos, o resultado dessa ação, poderá facilitar a geração das informações exigidas pelas autoridades fiscais, de maneira mais célere e completa. A atuação exclusiva do departamento tributário da empresa não é suficiente para atender com excelência todos os aspectos obrigatórios.

De acordo com os entrevistados, após a implementação da ECF a empresa de auditoria objeto desse trabalho, realizou investimentos perceptíveis aos seus profissionais em outros departamentos internos, principalmente nas áreas de tecnologia, consultoria e treinamento. Sendo que o investimento percebido com a tecnologia foi consideravelmente maior, quando comparado com a consultoria e treinamentos.

Ainda, a tecnologia foi considerada indispensável para a revisão ou o preenchimento da ECF, e dessa maneira, $85 \%$ dos entrevistados observaram que os próprios clientes tiveram que aderir à novas ferramentas tecnológicas para cumprir essa exigência legal. 
Gimenez, L., Oliveira, A. B. S., Carvalho, F. J. P.; SPED - Sistema Público de Escrituração Digital: Percepção das Empresas de Auditoria em relação os impactos de sua adoção

Novos produtos de consultoria surgiram com a alteração da maneira que o Imposto de Renda das Pessoas Jurídicas é declarado, dentre eles, foram citados a revisão de obrigações acessórias que influenciam no preenchimento (ECD), a revisão de procedimentos adotados pelas empresas para a composição do custo (Registro L210) e o auxílio na avaliação da necessidade de abertura de subcontas.

O questionário demonstrou que $45 \%$ dos entrevistados entenderam que houve muita adesão aos novos serviços gerados a partir do surgimento da ECF, sendo que todos perceberam no mínimo alguma adesão.

Tabela 2 - Adesão de novos serviços

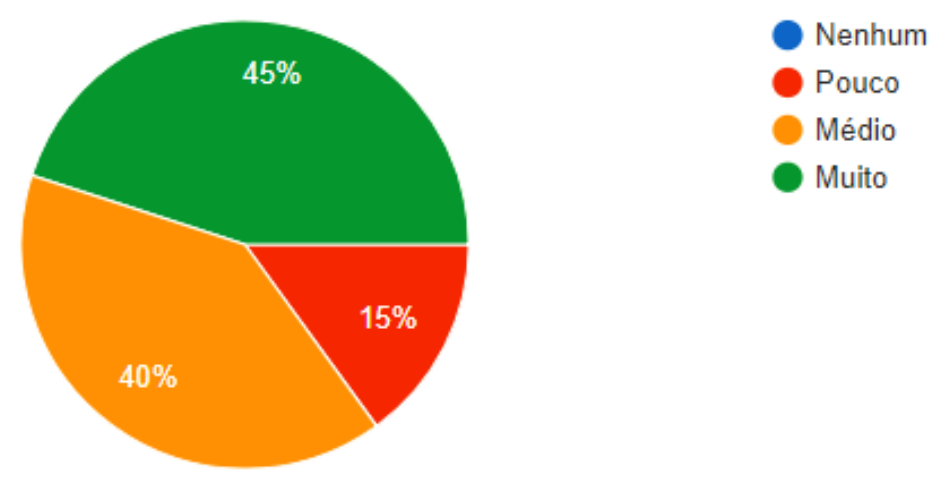

Fonte: elaboração própria

Com relação ao investimento em treinamentos, constatou-se que nem todos os entrevistados souberam responder o tempo e o valor investido na qualificação dos profissionais, mas a maioria entende que todas as categorias (do staff ao corpo gerencial) receberam treinamentos e $80 \%$ os consideram importantes ou essenciais para a prática efetiva dos projetos relacionados à ECF.

De acordo com o gráfico abaixo, a complexidade das informações necessárias para a transmissão das obrigações acessórias, foi classificada como alta para ECF e média para a DIPJ, corroborando a necessidade de maior preparação e investimento em treinamentos aos profissionais envolvidos. 
Gimenez, L., Oliveira, A. B. S., Carvalho, F. J. P.; SPED - Sistema Público de Escrituração Digital: Percepção das Empresas de Auditoria em relação os impactos de sua adoção

Tabela 3 - Investimentos em treinamentos de profissionais

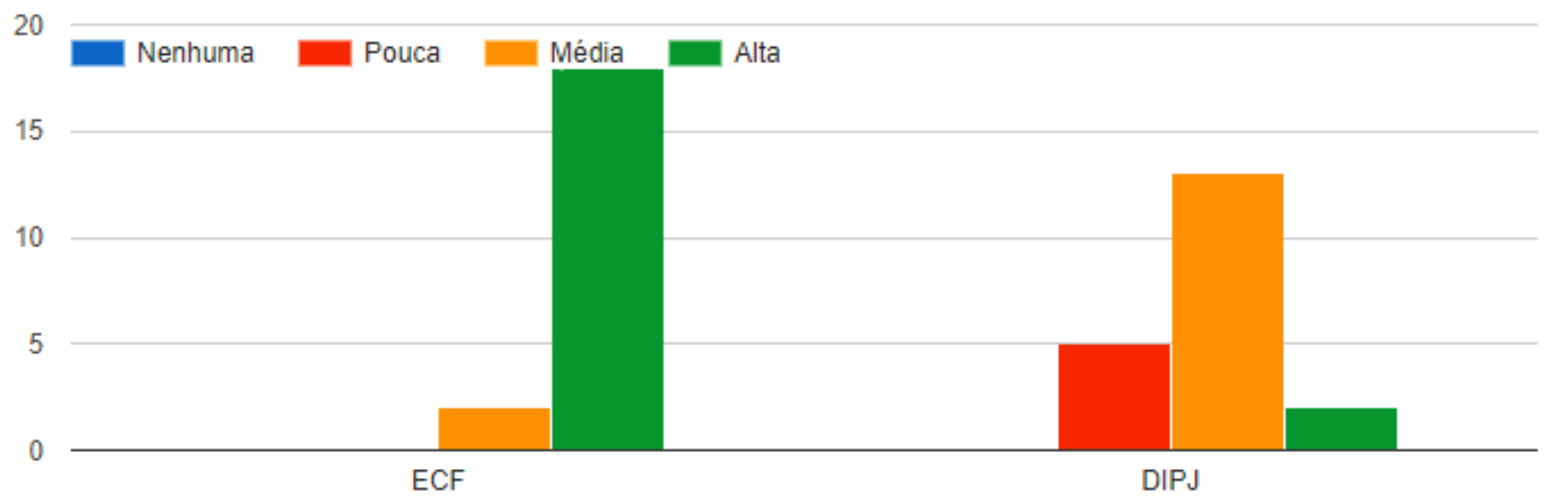

Fonte: elaboração própria

Outra abordagem fundamental apresentada pelos entrevistados, elencou as principais diferenças destacadas entre as referidas obrigações acessórias. Na opinião de muitos, a DIPJ exigia informações de forma aglutinada, ou seja, as informações eram mais globais, já a ECF depende de controles e dados adicionais de forma detalhada.

Ainda reportaram que na ECF, não havia necessidade de importar os balancetes mensais da empresa ou até mesmo utilizar informações contidas na Escrituração Contábil Digital (ECD), (obrigação acessória com prazo anterior ao da ECF) que atualmente é considerada essencial para o envio da referida obrigação acessória, pois na ausência dessa há impedimento do envio à RFB.

A DIPJ não refletia a abertura dos cálculos mensais da empresa, ou seja, era demonstrado apenas o lucro real de cada mês, sendo que somente no cálculo anual, havia abertura dos ajustes na realizados na base de cálculo do imposto de renda e da contribuição social. Na ECF o cálculo CSLL é detalhado mensalmente, contendo todas as adições e exclusões vinculadas preferencialmente com contas de balancete / LALUR.

A ECF passou, ainda, a exigir informações mais detalhadas a respeito de investimentos no exterior, além da demonstração minuciosa das provisões contidas na parte B do LALUR, criando assim registros específicos para reportar esses dados.

Consequentemente, há mais cruzamentos efetuados pela RFB, desta forma, é notório o aumento das análises em função da quantidade de informações complementares exigidas atualmente.

Em relação aos impactos gerados nos clientes, há perceptível dificuldade de entendimento e análise crítica por parte dos responsáveis pelo preenchimento da obrigação acessória (representantes dos clientes), mas, ao mesmo tempo, notou-se maior preocupação com a qualidade das informações transmitidas às autoridades fiscais quando comparado à DIPJ.

Muitos clientes investiram no aumento na demanda de softwares que auxiliam no preenchimento da ECF, contrataram consultorias voltadas à revisão do preenchimento, além de implementarem treinamentos e novos recursos destinados aos funcionários.

Também foi mencionado que devido ao grau de dificuldade da ECF, houve a necessidade da revisão dos controles internos, bem como a implementação de novo suportes, que têm como objetivo facilitar o preenchimento ou até mesmo auxiliá-los em eventual fiscalização. 
Gimenez, L., Oliveira, A. B. S., Carvalho, F. J. P.; SPED - Sistema Público de Escrituração Digital: Percepção das Empresas de Auditoria em relação os impactos de sua adoção

Por fim, em relação a receita, dos participantes que souberam responder, muitos entendem que a receita obtida pela empresa de auditoria no preenchimento da ECF aumentou em comparação com a DIPJ. Já nos trabalhos de revisão não houve alteração significativa, ou seja, o aumento foi menor, conforme demonstrado no quadro a seguir:

Tabela 4 - Receita proveniente dos trabalhos relacionados à ECF

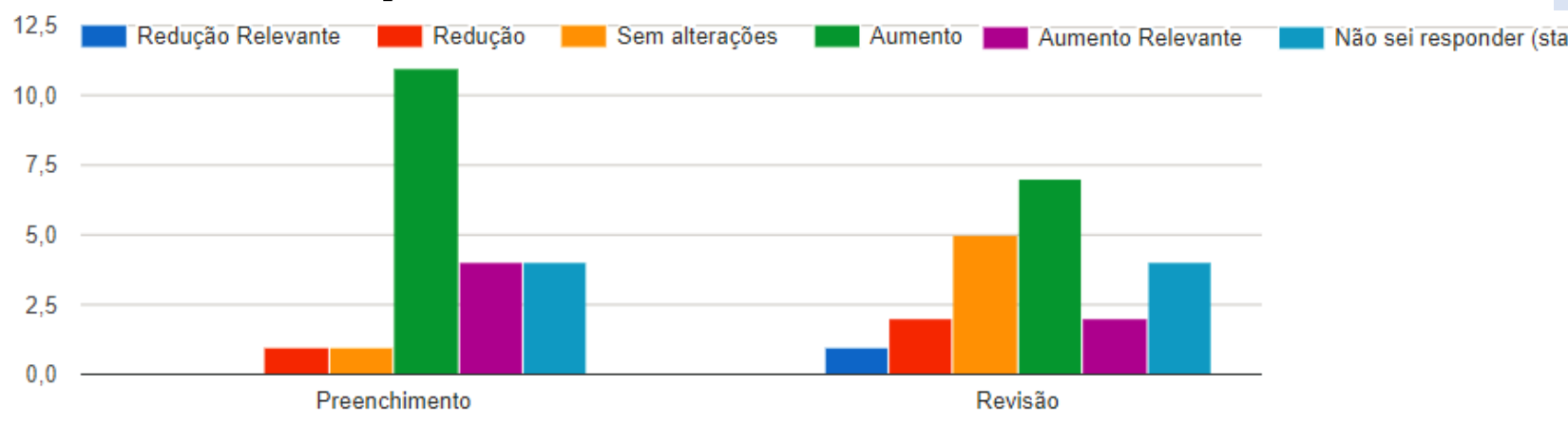

Fonte: elaboração própria

Desta forma, pode-se observar que devido ao grau de dificuldade apresentado na ECF, muitos clientes optaram por contratar o serviço de preenchimento da empresa de auditoria, para eventualmente diminuir os riscos fiscais envolvidos, quanto a revisão, os trabalhos mantiveramse no mesmo grau de demanda em relação a DIPJ.

\section{Conclusões}

Esse trabalho teve como objetivo demonstrar quais foram os impactos causados após a implementação da ECF na empresa de auditoria e consultoria tributária objeto do estudo, além de apresentar as eventuais diferenças encontradas entre a referida obrigação acessória quando comparada com a DIPJ.

Desta forma, diante da pesquisa realizada, observamos que devido ao grau de complexidade apresentado na ECF, houve aumento na carga horária dos funcionários da empresa de auditoria e consultoria, tanto no preenchimento quanto na revisão da referida obrigação acessória, quando comparado com a anterior.

Adicionalmente, foi essencial o investimento em softwares adaptados, bem como treinamentos destinados à todas as categorias (do staff ao corpo gerencial), isto porquê, é fundamental a preparação adequada de todos os profissionais envolvidos e o entendimento de todas as informações exigidas pela legislação, e demonstrá-las corretamente, para evitar o questionamento e eventuais autuações das autoridades fiscais.

Ainda, constatamos que atualmente há a participação ativa de outros departamentos, tanto na empresa de auditoria como no próprio cliente, que auxiliam e facilitam o preenchimento da ECF. Esse envolvimento é considerado fundamental e de extrema importância, pois além de otimizar o tempo, gera maior segurança e confiabilidade nas informações prestadas à RFB.

A nova obrigação acessória, exige diversas informações adicionais, bem como realiza cruzamentos com a finalidade de validar os dados apresentados pelos contribuintes. A depender 
Gimenez, L., Oliveira, A. B. S., Carvalho, F. J. P.; SPED - Sistema Público de Escrituração Digital: Percepção das Empresas de Auditoria em relação os impactos de sua adoção

das divergências encontradas, haverá automaticamente pelo sistema validador da obrigação acessória, o impedimento do envio até a retificação adequada dos elementos.

Demonstrou-se ainda, a percepção dos profissionais dessa empresa nos clientes, em relação ao novo programa validador da RFB e quais foram as providências necessárias para reunir as informações e estarem aptos a cumprir as exigências legais.

Aspecto importante de ser mencionado, está relacionado ao aumento da qualidade das informações prestadas pelos clientes, pois os mesmo estão mais atentos e preocupados com as exigências legais.

A ECF trouxe grandes mudanças na demonstração do cálculo do Imposto de Renda e da Contribuição Social sobre o Lucro Líquido, esta exige maiores detalhes dos ajustes mensais, além de requerer os respectivos relacionamentos com as contas contábeis (adições permanentes) e além das contas contábeis, com a parte B do LALUR (adições temporárias). Além disso, as provisões receberam tratamento especial, sendo criado registro específico com a descrição e saldo de cada uma delas.

Após a implementação da ECF, as empresas de auditoria e consultoria, começaram a identificar novas oportunidades de serviços relacionados ao preenchimento da referida obrigação acessória, oferecendo assim, auxílio e revisão nos demais suportes, registros e documentos essenciais no envio.

Apesar da oportunidade desses novos serviços, as receitas angariadas não aumentaram na mesma proporção da dificuldade encontrada para realizar os mesmos serviços de revisão e preenchimento da obrigação acessória, quando comparado à DIPJ, bem como não fícou evidenciado aos profissionais o aumento significativo do faturamento decorrente da venda desses novos serviços mencionados.

Mencionamos anteriormente que o Governo faz parte do grupo de usuários interessados nas informações que são prestadas pelas empresas, e além de outros motivos, os mais importantes é avaliar a situação econômica e financeira destas, e se os tributos estão sendo calculados e recolhidos corretamente.

$\mathrm{O}$ avanço tecnológico presente na ECF, auxilia nessa avaliação das autoridades fiscais, pois as informações, além de exigirem uma riqueza de detalhes muito grande são prestadas eletronicamente, maneira que facilita o cruzamento com as declarações de outros contribuintes, e permite que a fiscalização seja realizada, ou no mínimo iniciada eletronicamente, evitando então a necessidade de profissionais para realizar.

Não menos importante, é possível o Governo realizar o cruzamento dessas informações presentes nessa obrigação acessória, com as demais obrigações prestadas dentro do ambiente do SPED, e há também o compartilhamento desses dados com os estados e municípios.

$\mathrm{Ou}$ seja, o contribuinte encontra atualmente necessidade de prestar muita atenção nas informações transmitidas.

Concluímos que notoriamente a ECF trouxe grandes benefícios tanto para os contribuintes quanto para o Fisco, pois ao passo que facilitou o processo de fiscalização, as empresas têm a necessidade de manter melhor controle das informações fiscais, econômicas e financeiras da empresa. 
Gimenez, L., Oliveira, A. B. S., Carvalho, F. J. P.; SPED - Sistema Público de Escrituração Digital: Percepção das Empresas de Auditoria em relação os impactos de sua adoção

Essa necessidade ajuda a eliminar a precariedade dos sistemas e procedimentos utilizados anteriormente e eventualmente podem auxiliar a identificar erros de gestão, implementar novas práticas melhorando a situação dessa empresa no mercado nacional e internacional.

\section{REFERÊNCIAS}

ALBERTI, Mauri José. O impacto da implantação do sistema público de escrituração digital - SPED nas empresas do setor têxtil e de confecção, segundo a percepção dos gestores das empresas. 2016. Dissertação (Mestrado em Controladoria Empresarial) Universidade Presbiteriana Mackenzie, São Paulo. Disponível em < http://tede.mackenzie.br/jspui/handle/tede/3175> . Acesso em: 13 nov. de 2017.

BRASIL. Constituição Federal (1988). Constituição da República Federativa do Brasil, 1988.

em: <http://www.planalto.gov.br/ccivil_03/constituicao/constituicaocompilado.htm>. Acesso em: 13 de nov. de 2017.

Decreto $\mathrm{n}^{\mathrm{o}}$ 6.022, de 22 de janeiro de 2007. Disponível em: <http://www.planalto.gov.br/ccivil_03/_ato2007-2010/2007/decreto/d6022.htm>. Acesso em: 13 nov. 2017.

Ministério do Planejamento. Desoneração e Administração tributária - Medida de Aperfeiçoamento do Sistema Tributário - em implementação. Disponível em: <http://www.pac.gov.br/sobre-o-pac/medidas/desoneracao-e-administracao-tributaria $>$.

Acesso em: 13 de nov. de 2017.

_. Secretaria da Receita Federal. Instrução Normativa RFB No 1422, de 19 de dezembro $\begin{array}{lcc}2013 . & \text { Disponível } & \text { em: } \\ \text { <http://normas.receita.fazenda.gov.br/sijut2consulta/link.action?visao=anotado\&idAto }=48711\end{array}$ $>$. Acesso em: 13 de nov. de 2017.

Secretaria da Receita Federal. Sistema Público de Escrituração Digital. Benefícios. Disponível em: <http://sped.rfb.gov.br/pagina/show/965 >. Acesso em: 21 de nov. de 2017a.

- Secretaria da Receita Federal. Sistema Público de Escrituração Digital. Apresentação. Disponível em: 〈http://sped.rfb.gov.br/pagina/show/964>. Acesso em: $13 \mathrm{de}$ nov. de $2017 b$.

Secretaria da Receita Federal. Sistema Público de Escrituração Digital. CT-e. Disponível em: <http://sped.rfb.gov.br/pagina/show/1126>. Acesso em: 13 de nov. de 2017c.

Secretaria da Receita Federal. Sistema Público de Escrituração Digital. ECD. Disponível em: <http://sped.rfb.gov.br/pagina/show/499>. Acesso em: 13 de nov. de 2017d.

Secretaria da Receita Federal. Sistema Público de Escrituração Digital. ECF. Disponível em: <http://sped.rfb.gov.br/pagina/show/1285>. Acesso em: 13 de nov. de 2017e. 
Gimenez, L., Oliveira, A. B. S., Carvalho, F. J. P.; SPED - Sistema Público de Escrituração Digital: Percepção das Empresas de Auditoria em relação os impactos de sua adoção

. Secretaria da Receita Federal. Sistema Público de Escrituração Digital. EFD ICMS IPI. Disponível em: <http://sped.rfb.gov.br/pagina/show/523>. Acesso em: 13 de nov. de $2017 \mathrm{f}$.

Secretaria da Receita Federal. Sistema Público de Escrituração Digital. EFD Contribuições. Disponível em: <http://sped.rfb.gov.br/pagina/show/284>. Acesso em: 13 de nov. de $2017 \mathrm{~g}$.

BRASIL. Secretaria da Receita Federal. Sistema Público de Escrituração Digital. EFDReinf. Disponível em: <http://sped.rfb.gov.br/pagina/show/1494>. Acesso em: 13 de nov. de $2017 \mathrm{~h}$.

Secretaria da Receita Federal. Sistema Público de Escrituração Digital. eSocial. Disponível em: <http://sped.rfb.gov.br/pagina/show/1507>. Acesso em: 13 de nov. de $2017 \mathrm{i}$.

Secretaria da Receita Federal. Sistema Público de Escrituração Digital. NF-e. Disponível em: <http://sped.rfb.gov.br/pagina/show/1328>. Acesso em: 13 de nov. de 2017j.

Secretaria da Receita Federal. Sistema Público de Escrituração Digital. NFS-e. Disponível em: <http://sped.rfb.gov.br/pagina/show/488>. Acesso em: 13 de nov. de 2017k.

Secretaria da Receita Federal. Sistema Público de Escrituração Digital. NFC-e. Disponível em: <http://sped.rfb.gov.br/pagina/show/1519>. Acesso em: 13 de nov. de 20171.

Secretaria da Receita Federal. Sistema Público de Escrituração Digital. MDF-e. Disponível em: <http://sped.rfb.gov.br/pagina/show/1515>. Acesso em: 13 de nov de 2017m.

CONDÉ, Robson. Augusto; QUINTAL, Renato Santiago. Os impactos da Tecnologia da Informação e Comunicação no trabalho de auditoria fiscal: um estudo no âmbito de uma Secretaria de Fazenda. Tecnologia e Sociedade. Revista Tecnologia e Sociedade, v. 11, núm. 23, Júlio-dezembro de 2015, p. 215-237. 2015. Universidade Tecnológica Federal do Paraná, Curitiba, Brasil. Disponível em <http://www.redalyc.org/articulo.oa?id=496650345014>. Acesso em: 13 de nov. de 2017.

CULAU, Ariosto Antunes; FORTES, Martin Francisco de Almeida. Transparência e controle social na administração pública brasileira: avaliação das principais inovações introduzidas pela Lei de Responsabilidade Fiscal. In: Congresso Internacional del CLAD sobre la Reforma del Estado y de la Administración Pública, XI., 2006, Ciudad de Guatemala. Disponível em <http://igepp.com.br/uploads/arquivos/igepp_-_camara_transparenciacontrolesocial-1rf_leonardo_albernaz_200514_(1).pdf.> Acesso em: 21 de nov. de 2017.

DESLAURIERS, Jean-Pierre. Recherche qualitative: Guide pratique. Montreal: Cheneliere, p. 58, $1991 \mathrm{In}:$ GERHARDT, Tatiana Engel; SILVEIRA, Denis Toldo. (Org.). Métodos de Pesquisa. 1., Porto Alegre: Editora da Universidade Federal do Rio Grande do Sul, 2009. Disponível em <http://www.ufrgs.br/cursopgdr/downloadsSerie/derad005.pdf>. Acesso em: 11 de nov. de 2017. 
Gimenez, L., Oliveira, A. B. S., Carvalho, F. J. P.; SPED - Sistema Público de Escrituração Digital: Percepção das Empresas de Auditoria em relação os impactos de sua adoção

GERHARDT, Tatiana Engel; SILVEIRA, Denis Toldo. (Org.). Métodos de Pesquisa. 1., Porto Alegre: Editora da Universidade Federal do Rio Grande do Sul, 2009. Disponível em <http://www.ufrgs.br/cursopgdr/downloadsSerie/derad005.pdf>. Acesso em: 11 de nov. de 2017.

GOLDENBERG, M. A arte de pesquisar: como fazer pesquisa. 8. ed. Rio de Janeiro: Record, 2004. Disponível em < https://docs.google.com/file/d/0B3ACsS8GcONYNTEwODB1ZGQtNThkMC00YzQ4LTg2N jAtZTY1MzUxZmUzNmZh/edit>. Acesso em: 21 de nov. de 2017.

Hendriksen, E. S., \& Van-Breda, M. F. (1999). Teoria da Contabilidade. São Paulo: Editora Atlas.

IOB. Contabilidade - Usuários das informações contábeis, 2006. Disponível em < http://www.iob.com.br/noticiadb.asp?area=contabil\&noticia=59785 >. Acesso em: 21 de nov. de 2017.

MORETTI, Geizilene Machado. Os Impactos Causados Com A Implantação Do Sistema Público De Escrituração Fiscal Digital - SPED Fiscal: Uma Pesquisa Com Empresas De Transporte De Cargas Da Região Amrec. Criciúma, 2013. Monografia de conclusão de curso. (Bacharel em Ciências Contábeis) - Universidade do Extremo Sul Catarinense, UNESC. Disponível em: < http://biblioteca.portalbolsasdeestudo.com.br/link/?id=25895103>. Acesso em: 13 de nov. de 2017

PAIXÃO, et al. Os impactos da implantação do Sped Fiscal em uma empresa do setor de alimentação e sua relação com a governança corporativ. In: Encontro de Iniciação à Pesquisa, XXI., 2015, Fortaleza. Fortaleza, 2015. Estudo de Caso. Disponível em: <http://uol.unifor.br/oul/conteudosite/?cdConteudo=6121125>. Acesso em: 13 de nov. de 2017

POPE, Catherine; MAYS, Nick. Reaching the parts other methods cannot reach: an introduction to qualitative methods in health and health service research. British Medical Journal: $\mathrm{n}$ 311, p 42-45. 199. Disponível em: <https://www.ncbi.nlm.nih.gov/pmc/articles/PMC2550091/>. Acesso em: 21 de nov. de 2017.

RUSCHEL, Marcia Erna; FREZZA, Ricardo; UTZIG, Mara Jaqueline Santore. O impacto do SPED na Contabilidade desafios e perspectivas do profissional contábil. REVISTA CATARINENSE DA CIÊNCIA CONTÁBIL - CRCSC, Florianópolis: v. 10, n. 29, p. 09-26, dez. 2011.2 Disponível em: <http://revista.crcsc.org.br/index.php/CRCSC/article/view/1215/1149>. Acesso em: 13 de nov. de 2017.

SANOMIA, Priscila Costa. O Impacto do Sistema Público de Escrituração Digital (SPED) sobre os Escritórios de contabilidade do município de Cacoal-RO. Cacoal-RO, 2011. Monografia de conclusão de curso. (Bacharel em Ciências Contábeis) - Fundação Universidade Federal de Rondônia - $\quad$ UNIR. Disponível em: <http://www.ri.unir.br/jspui/handle/123456789/171>. Acesso em: 21 de nov. de 2017. 
Gimenez, L., Oliveira, A. B. S., Carvalho, F. J. P.; SPED - Sistema Público de Escrituração Digital: Percepção das Empresas de Auditoria em relação os impactos de sua adoção

SEBOLD, Marcia et al. Evolução da contabilidade brasileira: do governo eletrônico ao sistema público de escrituração digital - SPED. ENFOQUE: Reflexão Contábil, Maringá: Universidade Estadual de Maringá, v. 31, n.2, p. 23-32, mai.-ago. 2012. Disponível em: <http://www.redalyc.org/articulo.oa?id=307124727003>. Acesso em: 21 de nov. de 2017.

VEIGA, David Fernando da. Os Impactos provocados em algumas empresas de DouradosMS com a implantação do SPED- Sistema Público de Escrituração Digital. Dourados-MS, 2015. Monografia de conclusão de curso. (Bacharel em Ciências Contábeis) - Universidade Federal da Grande Dourados - UFGD. Disponível em: <https://dspace.ufgd.edu.br/jspui/bitstream/123456789/331/1/DAVIDVEIGA.pdf003>. Acesso em: 21 de nov. de 2017. 